\title{
Recent advances in breast cancer treatment
}

\author{
Polly SY Cheung *, FRCS (Glasg), FRACS \\ Specialist in General Surgery, private practice, Hong Kong \\ *Corresponding author: pollyc@pca.hk \\ Hong Kong Med J 2018;24:6-8 \\ DOI: 10.12809/hkmj175077
}

\section{Introduction}

Breast cancer is an important health hazard in Hong Kong women. It has been the number one cancer to affect women in Hong Kong for two decades and the number of new cases diagnosed each year is increasing. ${ }^{1}$ Today, one in 16 women will have breast cancer in their lifetime. ${ }^{1}$ The local pattern of breast cancer is similar to that in the West, suggesting that a westernised lifestyle and diet may be the underlying driving force.

Owing to advances in a multidisciplinary approach to treatment, breast cancer is no longer solely a surgical disease. An understanding of the tumour biology has led to the development of targeted medical therapy and hence improved outcome for breast cancer treatment. Less radical surgery in appropriate patients and new techniques in radiotherapy have reduced treatment morbidity and improved quality of life for breast cancer survivors.

\section{Molecular subtype of breast cancer}

Breast cancer is a heterogeneous disease. An understanding of the tumour biology has been made possible from gene expression array analysis, leading to the identification of different intrinsic subtypes that exhibit different tumour behaviour with different prognoses, and that may require specific targeted therapies to maximise treatment effectiveness. ${ }^{2}$ The assay of hormone receptor (oestrogen/progesterone receptor)-related genes, human epidermal growth factor receptor 2 (HER2)-related genes, basallike genes, and proliferation genes has led to the distinction of at least five intrinsic subtypes, namely luminal A and B, HER2-overexpressed, basal-like, and claudin-low, with the latter two being grouped as triple-negative subtypes. Clinical assays using immunohistochemistry measure surrogates that are used to differentiate the different biological subtypes and guide treatment.

\section{Targeted therapy for HER2- positive breast cancer}

Approximately $20 \%$ to $25 \%$ of all breast cancers exhibit HER2 overexpression. The development of the first anti-HER2-targeted therapy with trastuzumab more than 15 years ago has significantly improved the survival of breast cancer patients in both neoadjuvant, adjuvant, and metastatic settings. ${ }^{3}$ Newer agents such as lapatinib, pertuzumab, and an antibody-drug conjugate trastuzumab emtansine (T-DM1), have shown prolongation of diseasefree survival. ${ }^{4}$ Dual blockade using trastuzumab and pertuzumab has shown prolonged survival in patients with advanced HER2-positive cancer when compared with trastuzumab alone. ${ }^{5}$ Different clinical studies have also confirmed the value of T-DM1 as second- or third-line therapy for advanced breast cancer. ${ }^{6}$ The paper by Yeo et $\mathrm{al}^{7}$ in this issue reports the results of a multicentre retrospective study of the use of T-DM1 in advanced HER2-positive breast cancer in Hong Kong. It showed that T-DM1 was well tolerated and, despite heavy pretreatment with anti-HER2 agents and cytotoxic chemotherapy, a meaningful achievement of progression-free survival of 6 months was achieved.

Neratinib, a tyrosine kinase inhibitor, given after trastuzumab has been shown to reduce the risk of recurrence or death when compared with placebo, leading to a promising future for advanced HER2positive breast cancer. ${ }^{8}$

\section{Endocrine therapy for hormone receptor-positive breast cancer}

Approximately $75 \%$ of breast cancers express hormone receptors for oestrogen and progesterone. Tamoxifen, a selective oestrogen receptor modulator, was the first targeted therapy and has been used for more than 30 years to treat these hormone receptor-positive breast cancers. ${ }^{9}$ Recent treatment options have expanded to include agents such as aromatase inhibitors that reduce oestrogen synthesis, and selective oestrogen down-regulators such as fulvestrant. The use of these new agents has improved disease-free and overall survival.

Extended use of endocrine therapy using 10 years of tamoxifen ${ }^{10}$ or 5 years of tamoxifen followed by 5 years of aromatase inhibitors ${ }^{11}$ has been reported to reduce recurrence and mortality. For breast cancer with high risk of recurrence, continuation of endocrine therapy beyond 5 years should be considered, provided the side-effects of treatment are tolerable.

Some $20 \%$ to $30 \%$ of hormone-sensitive breast cancers may develop resistance with consequent recurrence or metastasis. Newer agents such as 
mTOR inhibitors, or CDK4/6 inhibitors, which target the altered pathways that produce endocrine resistance, have shown promising results when used in combination with anti-oestrogen agents. ${ }^{12,13}$

\section{Genomic testing of breast cancer}

Early-stage luminal cancers that are responsive to endocrine therapy may not require adjuvant chemotherapy. Genomic profile assays-such as the 21-gene assay (Oncotype DX; Genomic Health, Redwood City [CA], United States [US]), 70-gene assay (MammaPrint; Agendia, Amsterdam, Netherlands), PAM50 (Prosigna; NanoString Technologies Inc, Seattle [WA], US), and EndoPredict (Myriad Genetics Inc, Salt Lake City [UT], US) provide additional genomic information about the breast cancer, either by estimating the prognosis or predicting the additional benefit of chemotherapy in early-stage breast cancers. ${ }^{14,15}$ Studies using some of these assays have shown a reduced need for chemotherapy in about one third of patients who may otherwise be referred for chemotherapy on the basis of clinical and pathological parameters alone.

\section{Immunotherapy}

The promising results of immunotherapy in treating non-small-cell lung cancer and other cancers have led to clinical trials in breast cancer. An improved clinical activity has been observed in treating triplenegative breast cancer and those expressing PDL1. ${ }^{16}$ We await further results of clinical trials using immunotherapy.

\section{Less-extensive surgery for appropriate cancer}

Regular breast screening introduced in the 1970s has allowed detection of early breast cancer that may not require total mastectomy or complete axillary dissection, thereby reducing long-term morbidity. Long-term follow-up in studies started in the 1980s showed that breast-conserving surgery coupled with radiation has an equivalent outcome to total mastectomy in terms of survival. ${ }^{17}$ Today, one third of patients can receive breast-conserving treatment, which reduces the psychosocial impact of breast cancer on long-term survivorship.

The development of sentinel node biopsy in the mid-1990s has led to its use in clinically nodenegative tumours, thereby reducing the occurrence of lymphoedema that can cause long-term complications in breast cancer survivors. ${ }^{18}$

The randomised ACOSOG $\mathrm{Z} 11$ trial ${ }^{19}$ that compared sentinel node biopsy alone versus the addition of complete axillary dissection for sentinel node-positive patients has shown no difference in survival outcomes, leading to the recommendation that axillary dissection is no longer valid in patients who undergo breast-conserving treatment and postoperative systemic therapy. This approach has become increasingly adopted in many medical centres despite the criticism of under-recruitment of study cases.

For patients who still require total mastectomy for multicentric early disease, total skin-sparing mastectomy with preservation of the nipple areolar complex has shown no difference in local recurrence. It allows immediate breast reconstruction and maximises the aesthetic outcome of treatment. ${ }^{20}$ It has therefore gained increasing acceptance in treating carefully selected patients.

\section{New approach in radiotherapy}

Short-course radiotherapy using hypofractionation has been found to result in a similar outcome to standard radiotherapy in terms of local recurrence and survival, without increasing long-term toxicities. ${ }^{21}$ It is therefore now accepted as a standard of care for early-stage breast cancer.

Whole-breast radiation following breastconserving surgery aims to create a uniform dose distribution to target tissues with minimal toxicity to normal tissue. Clinical assessment and computed tomography-based treatment planning, together with techniques using compensators such as wedges, forward planning using segments, intensitymodulated radiotherapy, respiratory gating, or prone positioning, have all helped to achieve an optimal outcome.

Post-mastectomy radiotherapy is conventionally given to patients with involvement of four or more nodes to reduce locoregional failure and breast cancer mortality. For patients with one to three nodes, factors such as adverse tumour biology or tumour size of more than $5 \mathrm{~cm}$ may shift the decision to recommend radiotherapy after considering the benefits and toxicities. ${ }^{22}$

\section{Conclusion}

An improved understanding of the tumour biology of breast cancer has led to the identification of different intrinsic subtypes. Breast cancer care is now tailored to use the appropriate therapy to target the tumour characteristics of individual cancers, to achieve an improved survival outcome for breast cancer patients. Targeted cancer treatment is proliferating. More scientific work is required to further our understanding of the unknown subtypes, especially in triple-negative cancers, and elucidate the mechanisms that underlie the development of tumour resistance to drug therapy.

\section{Declaration}

The author has disclosed no conflicts of interest. 


\section{References}

1. Crude incidence rate of breast cancer in Hong Kong. Available from: https://www.hkbcf.org/article. php?aid=138\&cid=6\&lang=eng. Accessed 10 Jan 2018.

2. Cancer Genome Atlas Network. Comprehensive molecular portraits of human breast tumours. Nature 2012;490:61-70

3. Perez EA, Romond EH, Suman VJ, et al. Trastuzumab plus adjuvant chemotherapy for human epidermal growth factor receptor 2-positive breast cancer: planned joint analysis of overall survival from NSABP B-31 and NCCTG N9831. J Clin Oncol 2014;32:3744-52.

4. Swain SM, Baselga J, Kim SB, et al. Pertuzumab, trastuzumab, and docetaxel in HER2-positive metastatic breast cancer. N Engl J Med 2015;372:724-34.

5. Patel TA, Dave B, Rodriguez AA, Chang JC, Perez EA, Colon-Otero G. Dual HER2 blockade: preclinical and clinical data. Breast Cancer Res 2014;16:419.

6. Krop IE, Kim SB, González-Martín A, et al. Trastuzumab emtansine versus treatment of physician's choice for pretreated HER2-positive advanced breast cancer (TH3RESA): a randomised, open-label, phase 3 trial. Lancet Oncol 2014;15:689-99.

7. Yeo W, Luk MY, Soong IS, et al. Efficacy and tolerability of trastuzumab emtansine in advanced human epidermal growth factor receptor 2-positive breast cancer. Hong Kong Med J 2018;24:56-62.

8. Chan A, Delaloge S, Holmes FA, et al. Neratinib after trastuzumab-based adjuvant therapy in patients with HER2-positive breast cancer (ExteNET): a multicentre, randomised, double-blind, placebo-controlled, phase 3 trial. Lancet Oncol 2016;17:367-77.

9. Early Breast Cancer Trialists' Collaborative Group (EBCTCG), Davies C, Godwin J, Gray R, et al. Relevance of breast cancer hormone receptors and other factors to the efficacy of adjuvant tamoxifen: patient-level meta-analysis of randomised trials. Lancet 2011;378:771-84.

10. Davies C, Pan H, Godwin J, et al. Long-term effects of continuing adjuvant tamoxifen to 10 years versus stopping at 5 years after diagnosis of oestrogen receptor-positive breast cancer: ATLAS, a randomised trial. Lancet 2013;381:80516.

11. Goss PE, Ingle JN, Pritchard KI, et al. Extending aromataseinhibitor adjuvant therapy to 10 years. $\mathrm{N}$ Engl J Med 2016;375:209-19.

12. Piccart M, Hortobagyi GN, Campone M, et al. Everolimus plus exemestane for hormone-receptor-positive, human epidermal growth factor receptor-2-negative advanced breast cancer: overall survival results from BOLERO-2.
Ann Oncol 2014;25:2357-62.

13. Finn RS, Crown JP, Lang I, et al. The cyclin-dependent kinase 4/6 inhibitor palbociclib in combination with letrozole versus letrozole alone as first-line treatment of oestrogen receptor-positive, HER2-negative, advanced breast cancer (PALOMA-1/TRIO-18): a randomised phase 2 study. Lancet Oncol 2015;16:25-35.

14. Paik S, Tang G, Shak S, et al. Gene expression and benefit of chemotherapy in women with node-negative, estrogen receptor-positive breast cancer. J Clin Oncol 2006;24:372634.

15. Harris LN, Ismaila N, McShane LM, et al. Use of biomarkers to guide decisions on adjuvant systemic therapy for women with early-stage invasive breast cancer: American Society of Clinical Oncology Clinical Practice Guideline. J Clin Oncol 2016;34:1134-50.

16. Rugo HS, Delord JP, Im SA, et al. Preliminary efficacy and safety of pembrolizumab (MK-3475) in patients with PDL1-positive estrogen receptor-positive/HER2-negative advanced breast cancer enrolled in KEYNOTE-028 [abstract S5-07]. Proceedings of the San Antonio Breast Cancer Symposium; 2015 Dec 11.

17. Veronesi U, Cascinelli N, Mariani L, et al. Twenty-year follow-up of a randomized study comparing breastconserving surgery with radical mastectomy for early breast cancer. N Engl J Med 2002;347:1227-32.

18. Krag DN, Anderson SJ, Julian TB, et al. Sentinel-lymphnode resection compared with conventional axillarylymph-node dissection in clinically node-negative patients with breast cancer: overall survival findings from the NSABP B-32 randomised phase 3 trial. Lancet Oncology 2010;11:927-33.

19. Giuliano AE, Hunt KK, Ballman KV, et al. Axillary dissection vs no axillary dissection in women with invasive breast cancer and sentinel node metastasis: a randomized clinical trial. JAMA 2011;305:569-75.

20. Piper M, Peled AW, Foster RD, Moore DH, Esserman LJ. Total skin-sparing mastectomy: a systematic review of oncologic outcomes and postoperative complications. Ann Plast Surg 2013;70:435-7.

21. Whelan TJ, Pignol JP, Levine MN, et al. Long-term results of hypofractionated radiation therapy for breast cancer. $\mathrm{N}$ Engl J Med 2010;362:513-20.

22. Recht A, Comen EA, Fine RE, et al. Postmastectomy radiotherapy: an American Society of Clinical Oncology, American Society for Radiation Oncology, and Society of Surgical Oncology focused Guideline Update. Pract Radiat Oncol 2016;6:e219-34. 